\title{
Effects of Temperature, Time, Magnesium, and Copper on the Wettability of Al/TiC System
}

\author{
Halil Ibrahim Kurt and Murat Oduncuoglu \\ Technical Sciences, University of Gaziantep, 27310 Gaziantep, Turkey \\ Correspondence should be addressed to Halil Ibrahim Kurt; hiakurt@gmail.com \\ Received 7 January 2015; Accepted 22 April 2015 \\ Academic Editor: Giuseppe Vairo
}

Copyright (c) 2015 H. I. Kurt and M. Oduncuoglu. This is an open access article distributed under the Creative Commons Attribution License, which permits unrestricted use, distribution, and reproduction in any medium, provided the original work is properly cited.

\begin{abstract}
The effects of temperature, time, and the additions of magnesium and copper on the wetting behavior of $\mathrm{Al} / \mathrm{TiC}$ are studied theoretically. Mathematical formula is presented in explicit form. The effect of each variable is investigated by using the obtained equation. It is observed that the time and temperature have a stronger effect on the wetting of $\mathrm{TiC}$ in comparison to other input parameters. The proposed model shows good agreement with test results and can be used to find the wetting behavior of $\mathrm{Al} / \mathrm{TiC}$. The findings led to a new insight of the wetting process of TiC.
\end{abstract}

\section{Introduction}

One of the most important phenomena is the wetting of ceramic particles by molten metals, when metal matrix nanocomposites (MMNCs) are produced. During the processing stages of MMNCs, the wetting behavior plays an important role in the evolution of the microstructure and mechanical properties [1]. Titanium carbide (TiC) is an attractive reinforcing phase because of high chemical and thermal stability, extremely high hardness, low density, high melting point, and low coefficient of thermal expansion [2].

Wettability studies usually include the measurement of contact angles, which indicates the degree of wetting when a solid and a liquid interact. While large contact angles $\left(>90^{\circ}\right)$ correspond to low wettability, small contact angles $\left(<90^{\circ}\right)$ correspond to high wettability [3]. The wetting of ceramic particles by molten metals usually includes interfacial reactions [4]. The transfer and distribution of the load from the matrix to the reinforcement come true with a strong interfacial bonding. The interface reaction is dependent not only on temperature but also on time, the composition of the liquid, the volume of the liquid drop, and the size of the reaction zone. A change in any of these parameters will result in a change in the wetting process [5]. For example, if the temperature, time, and composition of the molten metal are changed, how does the wettability vary? Experimentally, this phenomenon is costly and time consuming. In many studies, the mathematical formulation is derived by researchers to reduce cost and save time [6-10].

The aim of this study is to investigate the effects of temperature, time, and chemical composition on the wettability of $\mathrm{Al} / \mathrm{TiC}$ and to obtain an explicit formulation. For this purpose, the contact angles were formulated by using MATLAB program.

\section{Experimental Procedures}

An extensive literature survey is performed for available experimental results [11-14]. The experimental results are divided in two sets, train and test data sets. The data sets for train and test are randomly selected from among experimental results where 94 sets are train set and 40 sets are test set, as shown in Tables 1 and 2, respectively. The input variables are temperature $(T)$, time, aluminum $(\mathrm{Al})$, magnesium $(\mathrm{Mg})$, and copper $(\mathrm{Cu})$ and the output variable is the contact angle $(\theta)$. Each input variable is scaled to the range of 0 to 1 by the following formula:

$$
x_{N}=\frac{x-x_{\min }}{x_{\max }-x_{\min }}
$$


TABLE 1: Train data set.

\begin{tabular}{|c|c|c|c|c|c|c|c|c|c|c|c|c|c|}
\hline & \\
\hline Number & $\begin{array}{c}T \\
\left({ }^{\circ} \mathrm{C}\right) \\
\end{array}$ & $\begin{array}{c}\text { Time } \\
(\min .)\end{array}$ & $\begin{array}{c}\mathrm{Al} \\
\text { (wt.\%) }\end{array}$ & $\begin{array}{c}\mathrm{Mg} \\
\text { (wt.\%) }\end{array}$ & $\begin{array}{c}\mathrm{Cu} \\
\text { (wt.\%) }\end{array}$ & $\theta$ & Number & $\begin{array}{c}T \\
\left({ }^{\circ} \mathrm{C}\right)\end{array}$ & $\begin{array}{l}\text { Time } \\
(\mathrm{min} .)\end{array}$ & $\begin{array}{c}\mathrm{Al} \\
\text { (wt.\%) }\end{array}$ & $\begin{array}{c}\mathrm{Mg} \\
\text { (wt.\%) }\end{array}$ & $\begin{array}{c}\mathrm{Cu} \\
\text { (wt.\%) }\end{array}$ & $\theta$ \\
\hline 1 & 750 & 90 & 79,25 & 20,75 & - & 64 & 48 & 1000 & 15 & 80 & - & 20 & 88 \\
\hline 2 & 750 & 60 & 79,25 & 20,75 & - & 60 & 49 & 900 & 20 & 79,25 & 20,75 & - & 42 \\
\hline 3 & 900 & 60 & 79,25 & 20,75 & - & 36 & 50 & 800 & - & - & 100 & - & 121 \\
\hline 4 & 900 & - & - & 100 & - & 119 & 51 & 800 & 40 & 95,86 & 4,14 & - & 114 \\
\hline 5 & 900 & 120 & 91,64 & 8,36 & - & 57 & 52 & 800 & 150 & 98,91 & 1,09 & - & 41 \\
\hline 6 & 800 & 20 & 100 & - & - & 86 & 53 & 800 & 60 & 95,86 & 4,14 & - & 97 \\
\hline 7 & 750 & - & 79,25 & 20,75 & - & 122 & 54 & 900 & - & 91,64 & 8,36 & - & 117 \\
\hline 8 & 900 & 30 & - & 100 & - & 20 & 55 & 750 & 150 & 79,25 & 20,75 & - & 56 \\
\hline 9 & 800 & 80 & 79,25 & 20,75 & - & 55 & 56 & 800 & 30 & 96 & - & 4 & 110 \\
\hline 10 & 900 & 80 & 79,25 & 20,75 & - & 35 & 57 & 750 & 60 & 95,86 & 4,14 & - & 115 \\
\hline 11 & 750 & 60 & 91,64 & 8,36 & - & 110 & 58 & 800 & 20 & 98,91 & 1,09 & - & 83 \\
\hline 12 & 800 & 15 & 96 & - & 4 & 115 & 59 & 900 & 150 & 79,25 & 20,75 & - & 31 \\
\hline 13 & 1000 & 15 & 96 & - & 4 & 78 & 60 & 900 & 30 & 96 & - & 4 & 90 \\
\hline 14 & 800 & 15 & 92 & - & 8 & 113 & 61 & 800 & 30 & 92 & - & 8 & 103 \\
\hline 15 & 750 & 40 & 98,91 & 1,09 & - & 123 & 62 & 850 & 30 & - & 100 & - & 91 \\
\hline 16 & 800 & 15 & 99 & - & 1 & 93 & 63 & 800 & 30 & - & 100 & - & 107 \\
\hline 17 & 900 & 60 & 100 & - & - & 58 & 64 & 800 & 60 & 79,25 & 20,75 & - & 58 \\
\hline 18 & 800 & 150 & 79,25 & 20,75 & - & 50 & 65 & 900 & 15 & 96 & - & 4 & 100 \\
\hline 19 & 900 & 10 & - & 100 & - & 41 & 66 & 900 & 15 & 99 & - & 1 & 80 \\
\hline 20 & 800 & 40 & 91,64 & 8,36 & - & 90 & 67 & 800 & 30 & 99 & - & 1 & 81 \\
\hline 21 & 900 & 40 & 95,86 & 4,14 & - & 61 & 68 & 900 & 80 & 95,86 & 4,14 & - & 60 \\
\hline 22 & 750 & 80 & 98,91 & 1,09 & - & 122 & 69 & 850 & 10 & - & 100 & - & 101 \\
\hline 23 & 900 & 15 & 67 & - & 33 & 85 & 70 & 900 & 30 & 99 & - & 1 & 72 \\
\hline 24 & 800 & 15 & 80 & - & 20 & 103 & 71 & 1000 & 15 & 99 & - & 1 & 67 \\
\hline 25 & 1000 & 30 & 67 & - & 33 & 63 & 72 & 900 & - & 100 & - & - & 125 \\
\hline 26 & 900 & 80 & 91,64 & 8,36 & - & 62 & 73 & 800 & 20 & 95,86 & 4,14 & - & 123 \\
\hline 27 & 800 & 80 & 95,86 & 4,14 & - & 83 & 74 & 900 & 150 & 91,64 & 8,36 & - & 52 \\
\hline 28 & 1000 & 30 & 80 & - & 20 & 69 & 75 & 1000 & 30 & 96 & - & 4 & 61 \\
\hline 29 & 1000 & 15 & 92 & - & 8 & 71 & 76 & 750 & 120 & 91,64 & 8,36 & - & 87 \\
\hline 30 & 800 & 150 & 95,86 & 4,14 & - & 64 & 77 & 800 & 20 & 79,25 & 20,75 & - & 77 \\
\hline 31 & 800 & 10 & - & 100 & - & 118 & 78 & 750 & 20 & 79,25 & 20,75 & - & 98 \\
\hline 32 & 900 & 150 & 95,86 & 4,14 & - & 58 & 79 & 750 & - & 98,91 & 1,09 & - & 127 \\
\hline 33 & 900 & 15 & 80 & - & 20 & 90 & 80 & 750 & 30 & 91,64 & 8,36 & - & 120 \\
\hline 34 & 750 & 120 & 79,25 & 20,75 & - & 59 & 81 & 900 & 15 & 92 & - & 8 & 102 \\
\hline 35 & 900 & 60 & 95,86 & 4,14 & - & 60 & 82 & 800 & 120 & 79,25 & 20,75 & - & 52 \\
\hline 36 & 750 & 60 & 98,91 & 1,09 & - & 123 & 83 & 900 & 30 & 80 & - & 20 & 78 \\
\hline 37 & 850 & 40 & - & 100 & - & 89 & 84 & 800 & 120 & 95,86 & 4,14 & - & 76 \\
\hline 38 & 900 & - & 79,25 & 20,75 & - & 113 & 85 & 900 & 150 & 100 & - & - & 45 \\
\hline 39 & 800 & 20 & 91,64 & 8,36 & - & 101 & 86 & 800 & 40 & - & 100 & - & 100 \\
\hline 40 & 900 & 40 & 91,64 & 8,36 & - & 89 & 87 & 750 & 80 & 95,86 & 4,14 & - & 114 \\
\hline 41 & 900 & 120 & 100 & - & - & 47 & 88 & 800 & 150 & 100 & - & - & 55 \\
\hline 42 & 800 & 15 & 67 & - & 33 & 100 & 89 & 900 & 30 & 92 & - & 8 & 86 \\
\hline 43 & 800 & - & 91,64 & 8,36 & - & 120 & 90 & 800 & 60 & 100 & - & - & 78 \\
\hline 44 & 900 & 20 & 95,86 & 4,14 & - & 73 & 91 & 900 & - & 95,86 & 4,14 & - & 118 \\
\hline 45 & 750 & 150 & 95,86 & 4,14 & - & 110 & 92 & 800 & - & 95,86 & 4,14 & - & 130 \\
\hline 46 & 900 & 30 & 67 & - & 33 & 75 & 93 & 800 & 120 & 100 & - & - & 57 \\
\hline 47 & 800 & 150 & 91,64 & 8,36 & - & 65 & 94 & 750 & 150 & 91,64 & 8,36 & - & 82 \\
\hline
\end{tabular}

TABLE 1: Continued. 
TABLE 2: Test data set.

\begin{tabular}{|c|c|c|c|c|c|c|}
\hline Number & $\begin{array}{c}T \\
\left({ }^{\circ} \mathrm{C}\right)\end{array}$ & $\begin{array}{l}\text { Time } \\
(\mathrm{min} .)\end{array}$ & $\begin{array}{c}\mathrm{Al} \\
(\mathrm{wt} . \%)\end{array}$ & $\begin{array}{c}\mathrm{Mg} \\
(\mathrm{wt} . \%)\end{array}$ & $\begin{array}{c}\mathrm{Cu} \\
(\mathrm{wt} . \%)\end{array}$ & $\theta$ \\
\hline 1 & 750 & 30 & 95,86 & 4,14 & - & 118 \\
\hline 2 & 800 & - & 100 & - & - & 125 \\
\hline 3 & 800 & 80 & 100 & - & - & 63 \\
\hline 4 & 900 & 120 & 95,86 & 4,14 & - & 60 \\
\hline 5 & 900 & 60 & 91,64 & 8,36 & - & 77 \\
\hline 6 & 1000 & 30 & 99 & - & 1 & 57 \\
\hline 7 & 750 & - & 95,86 & 4,14 & - & 120 \\
\hline 8 & 900 & 20 & 98,91 & 1,09 & - & 70 \\
\hline 9 & 800 & - & 98,91 & 1,09 & - & 120 \\
\hline 10 & 900 & 20 & 91,64 & 8,36 & - & 98 \\
\hline 11 & 800 & - & 79,25 & 20,75 & - & 136 \\
\hline 12 & 750 & 120 & 98,91 & 1,09 & - & 121 \\
\hline 13 & 800 & 120 & 98,91 & 1,09 & - & 44 \\
\hline 14 & 900 & 80 & 98,91 & 1,09 & - & 50 \\
\hline 15 & 750 & 120 & 95,86 & 4,14 & - & 114 \\
\hline 16 & 900 & 60 & 98,91 & 1,09 & - & 55 \\
\hline 17 & 900 & 80 & 100 & - & - & 52 \\
\hline 18 & 900 & - & 98,91 & 1,09 & - & 120 \\
\hline 19 & 800 & 40 & 98,91 & 1,09 & - & 67 \\
\hline 20 & 800 & 40 & 79,25 & 20,75 & - & 64 \\
\hline 21 & 800 & 80 & 91,64 & 8,36 & - & 77 \\
\hline 22 & 900 & 40 & 79,25 & 20,75 & - & 38 \\
\hline 23 & 800 & 60 & 91,64 & 8,36 & - & 80 \\
\hline 24 & 800 & 30 & 67 & - & 33 & 88 \\
\hline 25 & 750 & 150 & 98,91 & 1,09 & - & 120 \\
\hline 26 & 900 & 120 & 79,25 & 20,75 & - & 32 \\
\hline 27 & 800 & 30 & 80 & - & 20 & 93 \\
\hline 28 & 900 & 40 & 98,91 & 1,09 & - & 58 \\
\hline 29 & 1000 & 30 & 92 & - & 8 & 58 \\
\hline 30 & 900 & 150 & 98,91 & 1,09 & - & 46 \\
\hline 31 & 750 & 20 & 98,91 & 1,09 & - & 125 \\
\hline 32 & 750 & - & 91,64 & 8,36 & - & 127 \\
\hline 33 & 750 & 90 & 91,64 & 8,36 & - & 90 \\
\hline 34 & 850 & - & - & 100 & - & 120 \\
\hline 35 & 800 & 80 & 98,91 & 1,09 & - & 57 \\
\hline 36 & 900 & 120 & 98,91 & 1,09 & - & 47 \\
\hline 37 & 800 & 120 & 91,64 & 8,36 & - & 70 \\
\hline 38 & 1000 & 15 & 67 & - & 33 & 82 \\
\hline 39 & 900 & 20 & 100 & - & - & 72 \\
\hline 40 & 800 & 60 & 98,91 & 1,09 & - & 60 \\
\hline
\end{tabular}

where $x_{N}$ is the normalized value of variable $x$ and $x_{\max }$ and $x_{\min }$ are the maximum and minimum values of the variables, respectively.

Output values resulted from the model also in the range $[0,1]$ and transformed to its equivalent values based

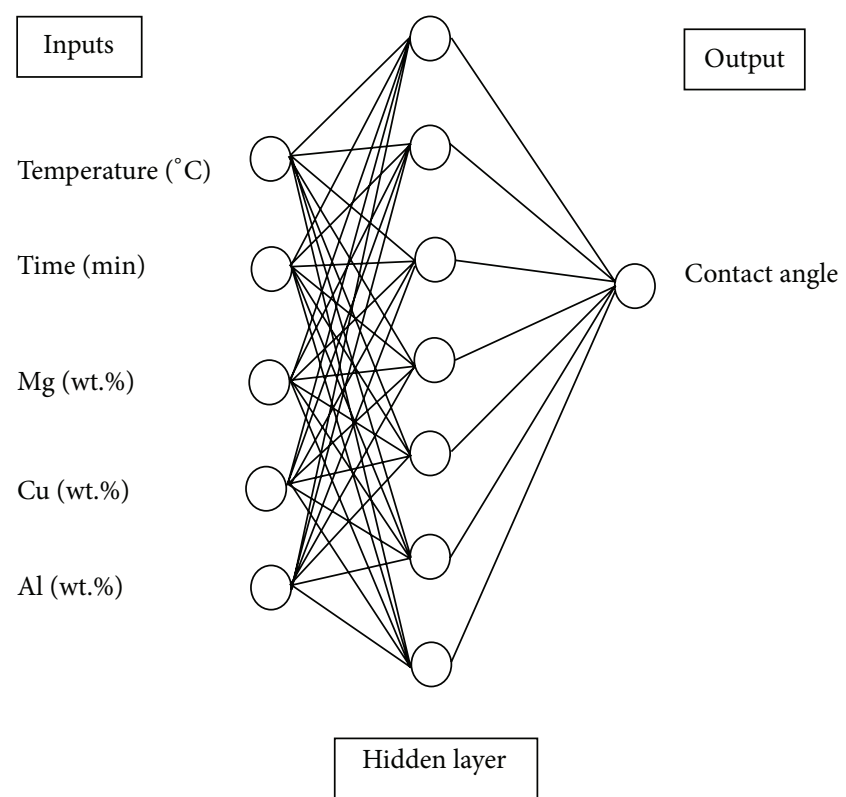

Figure 1: The model architecture.

on reverse method of normalization technique [15]. The unnormalized method is as

$$
x=x_{N}\left(x_{\max }-x_{\min }\right)+x_{\min } .
$$

MATLAB neural network (NN) toolbox is employed for the network training. Backpropagation (BP) learning algorithm with sigmoid function (Levenberg-MarquardtTrainlm), the most popular and effective supervised learning method, is used for training stage [16, 17].

\section{Results and Discussion}

One of the most important duties in NN works is the determination of layer numbers and neurons in the hidden layers. There is no well-defined procedure to find the optimal parameter settings and network architecture. The trial and error approach is used to determine the number of neurons in the hidden layer. The various neuron numbers (5-15) and hidden layers ( 1 and 2 ) are used in this study. It is observed that the optimal $\mathrm{NN}$ architecture is found to be $5-7-1 \mathrm{NN}$ architecture, as shown in Figure 1.

Figure 2 shows the correlation of $\mathrm{NN}$ and test data for train and test sets. $R^{2}$ values of train and test sets are 0.8311 and 0.8146 , respectively. $R^{2}$ value compares the accuracy of the model and a high $R^{2}$ value $\left(R^{2}=1\right)$ tells that all points lie exactly on the curve with no scatter and the result has a perfect correlation [18]. It is clear that all $R^{2}$ values are higher than 0.81 and the proposed model has high accuracy. In all stage of NN work, the effects of the temperature, time, and percent weights of $\mathrm{Mg}$ and $\mathrm{Cu}$ elements on the wetting behavior of $\mathrm{Al} / \mathrm{TiC}$ are quantified. It is clear from Figure 2 that there are deviations between the experimental and theoretical results. It is normal that the deviations are observed in $\mathrm{NN}$ works. These can be attributed to the formation and 


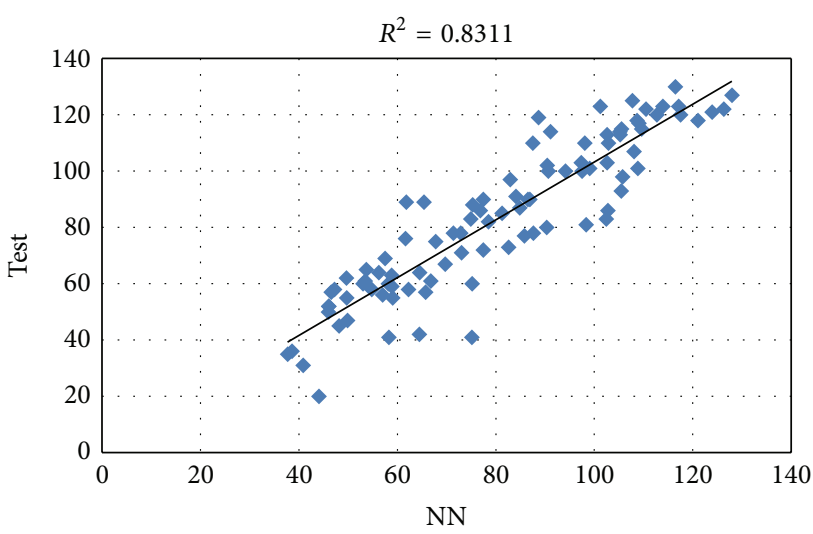

(a)

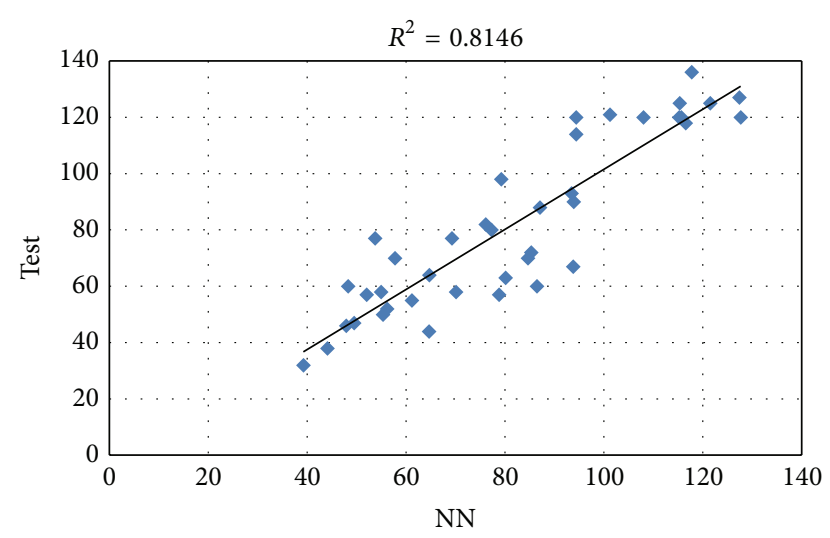

(b)

FIGURE 2: Correlation of NN and experimental results for (a) training set and (b) test set.

TABLE 3: Statistical parameters.

\begin{tabular}{lcc}
\hline & $R$ & MAE \\
\hline Train & 0.911 & 9.090 \\
Test & 0.903 & 10.205 \\
\hline
\end{tabular}

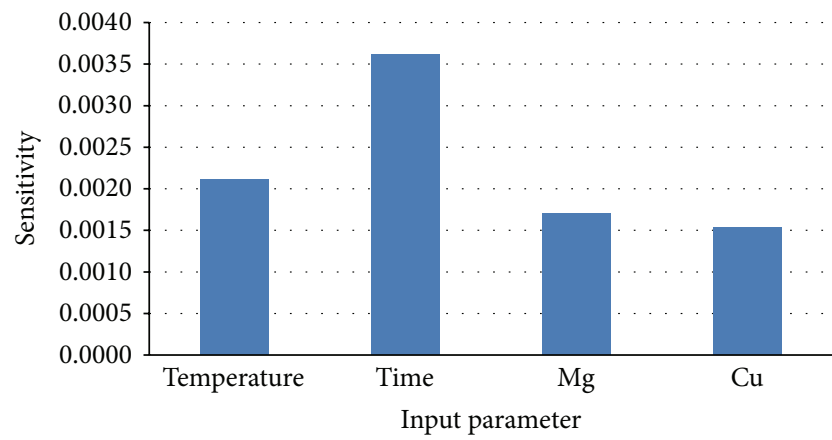

FIgURE 3: Sensitivity of input vectors.

volume fraction of the oxides and variation in experimental conditions. It is well known that the wettability of ceramic surfaces by metals and alloys is affected by some parameters such as time, temperature, composition, volatilization of $\mathrm{Mg}$, oxides ( $\mathrm{MgO}, \mathrm{MgAl}_{2} \mathrm{O}_{4}, \mathrm{Al}_{4} \mathrm{C}_{3}$, and $\mathrm{Al}_{2} \mathrm{O}_{3}$ ), and volume fraction of the oxides $[11,19]$. It is difficult to estimate the effect of each parameter on the wettability and it needs extensive studies. Nevertheless, " $R^{2}$," shown in Figure 2 , and " $R$," shown in Table 3 , values of training and test sets, indicate that the learning ability of $\mathrm{NN}$ is well enough.

Figure 3 demonstrates the sensitivity of input vectors on the wettability of $\mathrm{Al} / \mathrm{TiC}$ system. The different methods are used in order to estimate the sensitivity analysis [20]. A sensitivity analysis is done using the system to identify the effects of input parameters and their degree of importance on the output parameter. The training data set are used to estimate the sensitivity. It is well known that increasing data used in training process of $\mathrm{NN}$ enhances the ability of $\mathrm{NN}$. The basic idea of the analysis is that the input variables are shifted slightly and the corresponding change in the output is reported as a percentage. So, the relationship between the inputs and outputs of the network is revealed. As mentioned before, wetting behavior is affected by some parameters such as time, temperature, composition, volatilization of $\mathrm{Mg}$, oxides ( $\mathrm{MgO}, \mathrm{MgAl}_{2} \mathrm{O}_{4}, \mathrm{Al}_{4} \mathrm{C}_{3}$, and $\mathrm{Al}_{2} \mathrm{O}_{3}$ ), and volume fraction of the oxides. According to the done sensitivity analysis, it is observed that the time and temperature have a dominant effect on the wettability. In other words, any change in time and temperature in comparison to $\mathrm{Mg}$ and $\mathrm{Cu}$ levels will have significantly affected the wettability.

The performance of the model is evaluated by the correlation coefficient $(R)$ as in the following expression [21]:

$$
R=\frac{\operatorname{cov}\left(t_{i}, \widehat{t}_{i}\right)}{\sqrt{\operatorname{var}\left(t_{i}\right) \cdot \operatorname{var}\left(\widehat{t}_{i}\right)}} .
$$

Mean absolute error (MAE) is used as error evaluation criteria in order to facilitate the comparisons between predicted values and desired values according to the following equation:

$$
\operatorname{MAE}=\frac{1}{N} \sum_{i=1}^{N}\left|t_{i}-\widehat{t}_{i}\right|
$$

where $N$ is the total number of the data and $t_{i}$ and $\widehat{t}_{i}$ are the experimental value and predicted output values from $\mathrm{NN}$ model for a given input, respectively.

The statistical parameters of train and test data sets are shown in Table 3. The correlation coefficients and MAE in train and test sets are 0.911 and 0.903 and 9.090 and 10.205, respectively. A high $R$ value means that the model has high accuracy. The proposed model is in good agreement with the experimental data and all the errors are within acceptable ranges.

3.1. Formulation of the Model. The main aim is to obtain the explicit formula of the wettability as a function of input variables. The contact angle $(\theta)$ is determined by using the formula

$$
\theta=116 *\left(\frac{1}{1+e^{-v}}\right)+20
$$


where

$$
\begin{aligned}
v= & (-5.413) *\left(\frac{1}{1+e^{-u 1}}\right)+(-5.039) *\left(\frac{1}{1+e^{-u 2}}\right) \\
& +(4.471) *\left(\frac{1}{1+e^{-u 3}}\right)+(5.617) *\left(\frac{1}{1+e^{-u 4}}\right) \\
& +(-3.187) *\left(\frac{1}{1+e^{-u 5}}\right)+(-5.171) \\
& *\left(\frac{1}{1+e^{-u 6}}\right)+(1.940) *\left(\frac{1}{1+e^{-u 7}}\right)+(3.251),
\end{aligned}
$$

where

$$
\begin{aligned}
u 1= & (12.860 * X 1)+(-0.479 * X 2)+(-2.663 * X 3) \\
& +(4.828 * X 5)+(2.791 * X 6)+(3.189), \\
u 2= & (5.879 * X 1)+(0.198 * X 2)+(-3.548 * X 3) \\
& +(-0.218 * X 4)+(-2.365 * X 5) \\
& +(-4.276), \\
u 3= & (1.076 * X 1)+(1.848 * X 2)+(-0.015 * X 3) \\
& +(3.167 * X 4)+(1.939 * X 5)+(2.625), \\
u 4= & (-3.182 * X 1)+(-6.709 * X 2)+(-1.973 * X 3) \\
& +(3.004 * X 4)+(-1.407 * X 5)+(0.792), \\
u 5= & (-2.754 * X 1)+(11.393 * X 2)+(3.637 * X 3) \\
& +(-4.467 * X 4)+(1.088 * X 5)+(-1.209), \\
u 6= & (-0.053 * X 1)+(-2.200 * X 2)+(-4.219 * X 3) \\
& +(6.404 * X 4)+(-5.141 * X 5)+(1.100), \\
u 7= & (-3.957 * X 1)+(-4.811 * X 2)+(3.341 * X 3) \\
& +(-2.824 * X 4)+(-0.321 * X 5)+(0.639),
\end{aligned}
$$

where $X 1, X 2, X 3, X 4$, and $X 5$ are normalized values of temperature, time, $\mathrm{Al}, \mathrm{Mg}$, and $\mathrm{Cu}$ (wt.\%), respectively.

It should be noted that the explicit formulation is valid for the proposed ranges. The contact angles of $\mathrm{Al}, \mathrm{Mg}$, and $\mathrm{Cu}$ are 119,125 , and 130 , respectively [22-24]. For example, by using the designed equation, it is calculated that the contact angle value of $\mathrm{Al}-1 \mathrm{Mg}-5 \mathrm{Cu}$ alloy at $1000^{\circ} \mathrm{C}$ and 60 minute is $44.5 \pm 4$. It can be said that the wettability between $\mathrm{TiC}$ and $\mathrm{Al}$ matrix with $\mathrm{Mg}$ and $\mathrm{Cu}$ can be predicted by the advanced model with $90 \%$ accuracy.

\section{Conclusion}

In this work, the explicit mathematical formula is derived from NN model. The model has a high reliability rate and shows good agreement with experimental results. The mean absolute error for predicted values does not exceed $10.5 \%$. The sensitivity analysis of the developed model demonstrated that the time and temperature are the significant variables in affecting the wettability. The results also showed that the wetting of $\mathrm{TiC}$ by $\mathrm{Al}$ alloy with $\mathrm{Mg}$ and $\mathrm{Cu}$ can be predicted with $90 \%$ accuracy. Hence, it is concluded that the model is a successful and advantageous analytical tool for determining the wettability with considerable saving in cost and time.

\section{Conflict of Interests}

The authors declare that there is no conflict of interests regarding the publication of this paper.

\section{References}

[1] N. Froumin, N. Frage, M. Polak, and M. P. Dariel, "Wetting phenomena in the $\mathrm{TiC} /(\mathrm{Cu}-\mathrm{Al})$ system," Acta Materialia, vol. 48, no. 7, pp. 1435-1441, 2000.

[2] E. K. Storms, The Refractory Carbides, Academic Press, 1967.

[3] Y. Yuan and T. R. Lee, "Contact angle and wetting properties," in Surface Science Techniques, G. Bracco and B. Holst, Eds., vol. 51 of Springer Series in Surface Sciences, pp. 3-34, Springer, Berlin, Germany, 2013.

[4] H. Fujii, H. Nakae, and K. Okada, "Interfacial reaction wetting in the boron nitride/molten aluminum system," Acta Metallurgica Et Materialia, vol. 41, no. 10, pp. 2963-2971, 1993.

[5] C. Rado, S. Kalogeropoulou, and N. Eustathopoulos, "Bonding and wetting in non-reactive $\mathrm{metal} / \mathrm{SiC}$ systems: weak or strong interfaces?" Materials Science and Engineering A, vol. 276, no. 1-2, pp. 195-202, 2000.

[6] Y.-J. Chen, S.-C. Chen, and P.-J. Chen, "Prediction of depth of sedation from biological signals using continuous restricted Boltzmann machine," Mathematical Problems in Engineering, vol. 2014, Article ID 189040, 6 pages, 2014.

[7] F. Wang, S. Chen, J. Sun, D. Yan, L. Wang, and L. Zhang, "Time-frequency fault feature extraction for rolling bearing based on the tensor manifold method," Mathematical Problems in Engineering, vol. 2014, Article ID 198362, 15 pages, 2014.

[8] H. Ceylan, "Optimal design of signal controlled road networks using differential evolution optimization algorithm," Mathematical Problems in Engineering, vol. 2013, Article ID 696374, 11 pages, 2013.

[9] H. Ceylan, "An artificial neural networks approach to estimate occupational accident: a national perspective for Turkey," Mathematical Problems in Engineering, vol. 2014, Article ID 756326, 10 pages, 2014.

[10] H. Kurt and M. Oduncuoglu, "Formulation of the effect of different alloying elements on the tensile strength of the in situ Al- $\mathrm{Mg}_{2} \mathrm{Si}$ composites," Metals, vol. 5, no. 1, pp. 371-382, 2015.

[11] A. Contreras, E. Bedolla, and R. Pérez, "Interfacial phenomena in wettability of TiC by Al-Mg alloys," Acta Materialia, vol. 52, no. 4, pp. 985-994, 2004.

[12] A. Contreras, "Wetting of $\mathrm{TiC}$ by $\mathrm{Al}-\mathrm{Cu}$ alloys and interfacial characterization," Journal of Colloid and Interface Science, vol. 311, no. 1, pp. 159-170, 2007.

[13] A. Contreras, C. Angeles-Chávez, O. Flores, and R. Perez, "Structural, morphological and interfacial characterization of Al-Mg/TiC composites," Materials Characterization, vol. 58, no. 8-9, pp. 685-693, 2007.

[14] A. Contreras, C. A. León, R. A. L. Drew, and E. Bedolla, "Wettability and spreading kinetics of $\mathrm{Al}$ and $\mathrm{Mg}$ on $\mathrm{TiC}$," Scripta Materialia, vol. 48, no. 12, pp. 1625-1630, 2003. 
[15] A. M. Hassan, A. Alrashdan, M. T. Hayajneh, and A. T. Mayyas, "Prediction of density, porosity and hardness in aluminumcopper-based composite materials using artificial neural network," Journal of Materials Processing Technology, vol. 209, no. 2, pp. 894-899, 2009.

[16] A. Cevik, M. A. Kutuk, A. Erklig, and I. H. Guzelbey, "Neural network modeling of arc spot welding," Journal of Materials Processing Technology, vol. 202, no. 1-3, pp. 137-144, 2008.

[17] D. E. Rumelhart, G. E. Hinton, and R. J. Williams, "Learning internal representations by error propagation," in Parallel Distributed Processing: Explorations in the Microstructure of Cognition, E. R. David, L. M. James, and C. P. R. Group, Eds., vol. 1, pp. 318-362, MIT Press, 1986.

[18] C. C. Kin, M. M. Don, and Z. Ahmad, "Compressive strength prediction of concrete recycled aggregates made from ceramic tiles using feedforward artificial neural network (FANN)," in Computer Aided Chemical Engineering, A. K. Iftekhar and S. Rajagopalan, Eds., pp. 320-324, Elsevier, 2012.

[19] H. Abdeyazdan, N. Dogan, M. A. Rhamdhani, M. W. Chapman, and B. J. Monaghan, "Dynamic wetting of $\mathrm{CaO}-\mathrm{Al}_{2} \mathrm{O}_{3}-\mathrm{SiO}_{2}-$ $\mathrm{MgO}$ liquid oxide on $\mathrm{MgAl}_{2} \mathrm{O}_{4}$ spinel," Metallurgical and $\mathrm{Ma}$ terials Transactions B, vol. 46, no. 1, pp. 208-219, 2015.

[20] M. H. Shojaeefard, M. Akbari, M. Tahani, and F. Farhani, "Sensitivity analysis of the artificial neural network outputs in friction stir lap joining of aluminum to brass," Advances in Materials Science and Engineering, vol. 2013, Article ID 574914, 7 pages, 2013.

[21] A. Jahedsaravani, M. H. Marhaban, and M. Massinaei, "Prediction of the metallurgical performances of a batch flotation system by image analysis and neural networks," Minerals Engineering, vol. 69, pp. 137-145, 2014.

[22] P. Somasundaran, Encyclopedia of Surface and Colloid Science, Second Edition-Eight-Volume Set (Print), Taylor \& Francis, 2006.

[23] K. L. Mittal, Contact Angle, Wettability and Adhesion, Taylor \& Francis, New York, NY, USA, 2009.

[24] Q. A. Acton, Light Metals: Advances in Research and Application: 2011 Edition, Scholarly Editions, 2012. 


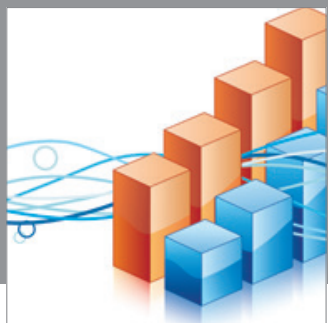

Advances in

Operations Research

mansans

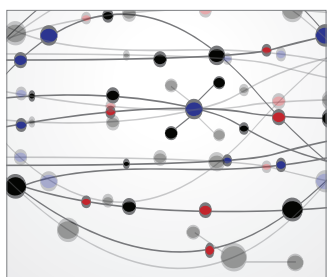

The Scientific World Journal
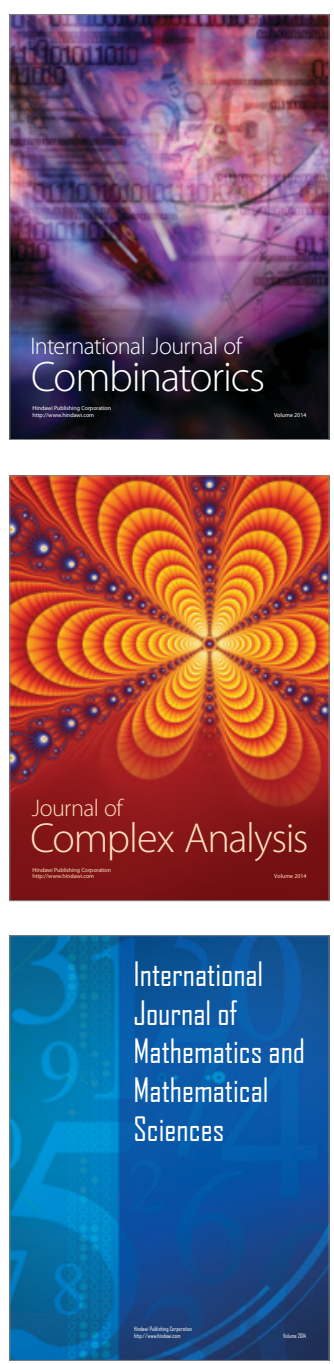
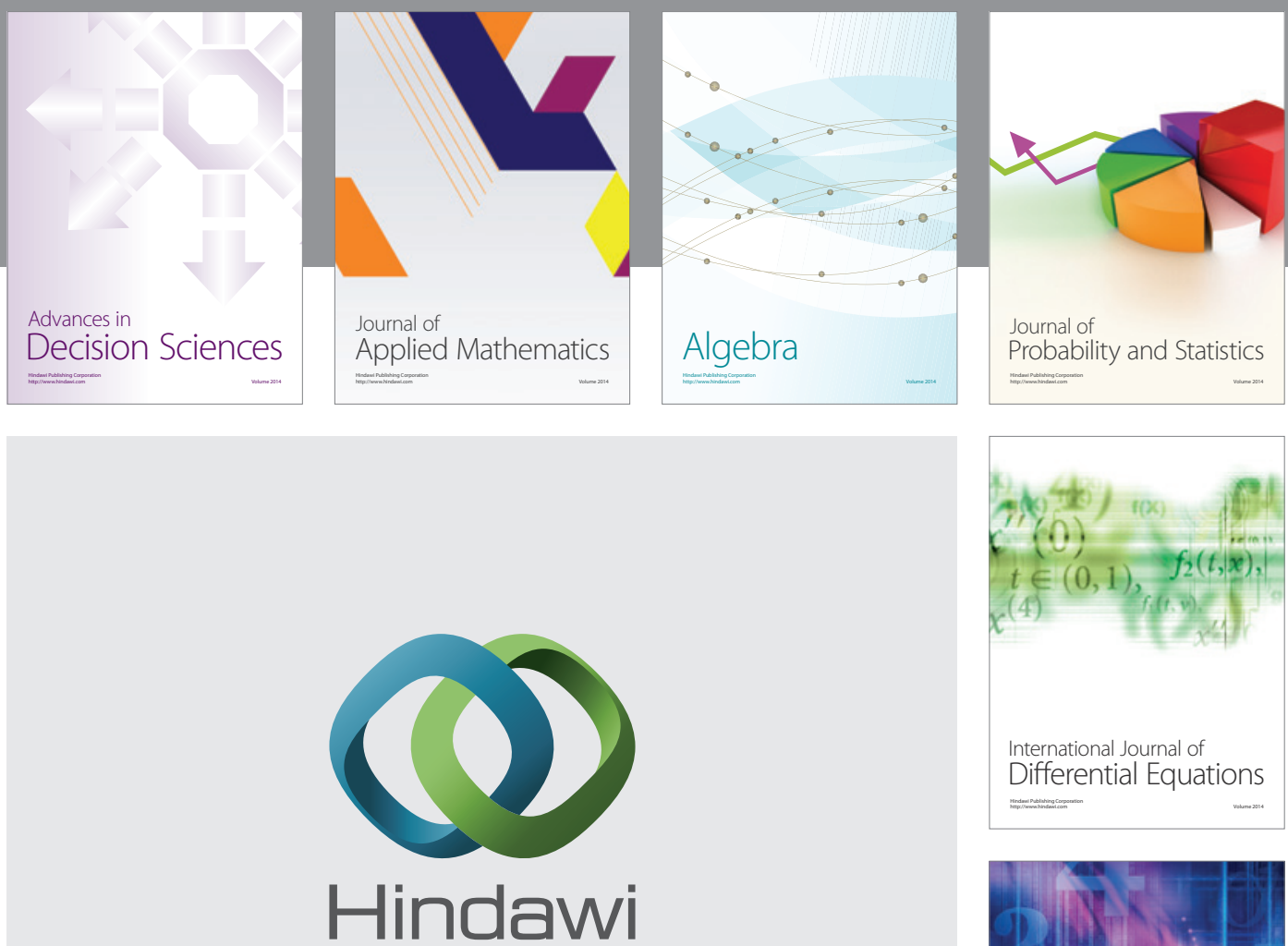

Submit your manuscripts at http://www.hindawi.com
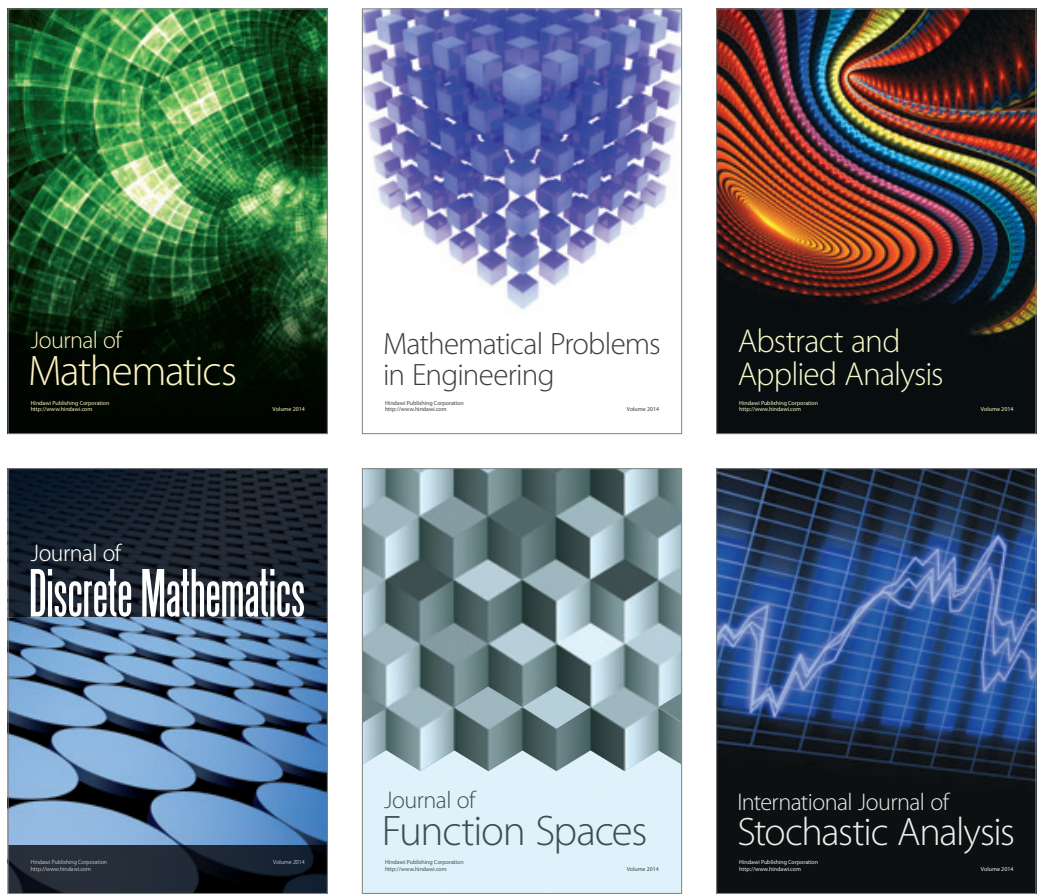

Journal of

Function Spaces

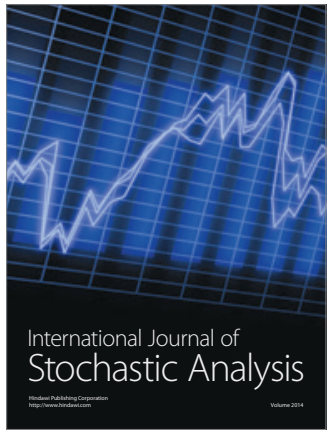

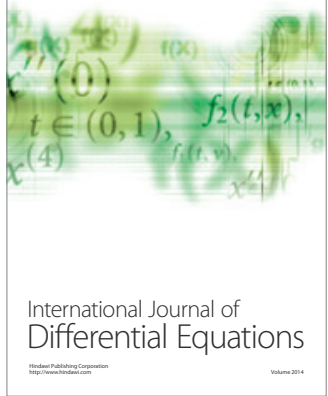
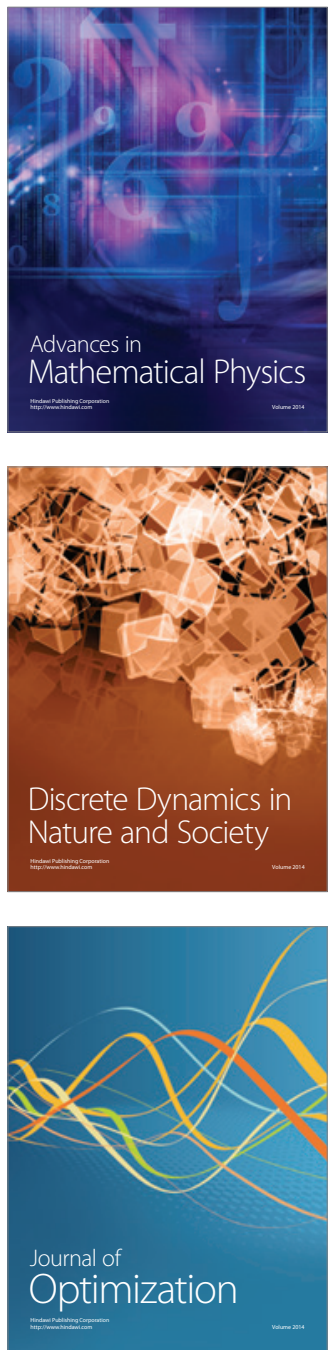